\section{Therapeutic Application of Au- tologous ADMSCS (Adipose Derived Mesenchymal Stem Cells) and Islet like Cell Ag- gregates (ICAS) Derived from them in Type 1 and 2 Diabetes Mellitus - A Proof of Concept Study}

\section{Jaymesh M Thadani ${ }^{1}$, Anant Marathe ${ }^{2 *}$, Bhaskar K Vyas ${ }^{3}$, Rajni B Vyas ${ }^{4}$, Ansarullah A A $^{5}$ Prashant Kshatriya ${ }^{6}$, Dhwani Modiv $^{7}$ and Shivani Vakodikar ${ }^{8}$}

${ }^{1}$ Total Potential Cells (P) Ltd, Parimal Majumdar Wada, Raopura, Vadodara, Gujarat

${ }^{2}$ Department of Zoology, Maharaja Sayajirao University of Baroda, Vadodara, Gujarat

\begin{abstract}
Background: The concept is based upon the properties of mesenchymal stem cells like angiogenesis, anti-inflammatory, immune-modulatory as well as trans-lineage translation of ADMSCs to ICAs and the hypothesis of multiple Intramuscular injections (IM) of Mesenchymal Stromal Cells (MSCs) at different sites would aid in countering the insulin resistance. This is a proof of concept report of treatment of seven patients, 2 with type I \& 5 with type II Diabetes.

Material and methods: 7 patients were enrolled ( 2 with type 1 and 5 with type 2 ) randomly. About 100 to $300 \mathrm{cc}$ of adipose tissue was aspirated from lower abdomen and processed to obtain mononuclear cells. Mononuclear cells were divided into two parts. Half of the mononuclear cells (SVF- Stromal Vascular Factor) were injected intramuscularly (dosage: 1-2 million cells per $\mathrm{kg} / \mathrm{body}$ weight) and the other half were processed for culture. The pure cultures of MSCs were passaged twice to get more number of cells. The protocol for MSCs isolation was established by phenotypic characterization of MSCS by surface markers. About 20 million of ADMSCs were translated to ICAs. This yielded up to 1000 ICAs. The
\end{abstract}

*Corresponding author: Anant Marathe, Total Potential Cells (P) Ltd, Parimal Majumdar Wada, Raopura, Vadodara, Gujarat, Tel: +919825 065842; E-mail: dranantmarathe@hotmail.com

Citation: Vyas BK, Vyas RB, Ansarullah A, Marathe A, Thadani JM, et al. (2016) Therapeutic Application of Autologous ADMSCS (Adipose Derived Mesenchymal Stem Cells) and Islet like Cell Aggregates (ICAS) Derived from them in Type 1 and 2 Diabetes Mellitus - A Proof of Concept Study. J Stem Cell Res Dev Ther 3: 08.

Received: April 15, 2016; Accepted: August 03, 2016; Published: August 16, 2016
ICAs were also characterized by their surface markers like Insulin and c-peptide and their insulin production after glucose challenge. ICAs were then injected intra hepatically through percutaneous route.

Result: The dosage of insulin decreased after intra muscular injection of ADMSCs combined with intra-hepatic injection of ICAs. No adverse effects including GVHD were noticed following the procedure.

Conclusion: All the 7 patients were benefitted and were satisfied with the outcome after follow up of 12 months.

Keywords: Adipose Derived Mesenchymal Stem Cells (ADMSCs); Diabetes type I \& II; Intra hepatic; Stromal Vascular Fraction (SVF)

\section{Introduction}

Stem cell therapy has potent therapeutic applications in various degenerative disorders. Mesenchymal Stem Cells (MSCs) are found in various tissues, including bone marrow, umbilical cord, placenta and adipose tissue [1]. They are immunonaive [2]. Adipose Derived Mesenchymal Stem Cells (ADMSCs) have the potential to undergo multilineage differentiation [3] i.e., mesoderm, ectoderm and endoderm. ADMSCs are also capable of angiogenesis, which facilitate engraftment of donor pancreatic islets when co-transplanted [4]. Anti inflammatory and immunomodulatory capabilities of ADMSCs facilitates enhanced engraftment of transplanted islets [4].

\section{The rationale of the novel protocols in this study is as follows;}

Diabetes is a group of metabolic diseases characterized by high levels of the glucose in the blood. This excess glucose is responsible for most of the complications of diabetes, which include blindness, kidney failure, heart disease, stroke, neuropathy and amputations. Type 2 diabetes, also called adult-onset diabetes, tends to affect older, sedentary and overweight individuals with a family history of diabetes. Type 2 diabetes occurs when the body cannot use insulin effectively. This is called insulin resistance and the result is the same as with type 1 diabetes-a build up of glucose in the blood.

\section{Type I diabetes}

Type 1 diabetes, also known as juvenile-onset diabetes, typically affects children and young adults. Diabetes develops when the body's immune system develops autoimmunity against its own beta cells. The immune mediated attack destroys the beta cells. As a result the insulin production becomes inadequate. In the absence of enough insulin, glucose cannot enter the cell and glucose accumulates in the blood.

Autoimmune destruction of B-Cells is a hallmark of type 1 diabetes (T1D). Immunomodulatory and proangiogenic roles of MSCs are used in this protocol to arrest $\beta$-cell destruction, preserve residual $\beta$-cell mass and prevent disease recurrence [5]. Secondly the ICAs derived from the ADMSCs further help in the control of blood sugar levels by producing Insulin.

The present study proposes the potential use of human Adipose Derived Mesenchymal Stem Cells (ADMSCs) to differentiate into functional Islet like Cell Aggregates (ICAs). Our modified differentiation protocol based on the protocol developed by 
Dr. Bhonde et al., used successfully to translate them to Islet like Cluster Aggregates (ICAs) in vitro to secrete insulin. These ICAs are shown to produce insulin and C-peptide in a glucose dependent manner exhibiting in-vitro functionality. The glucose challenge studies done in vitro verified by estimation of insulin and C-peptide levels. The decreased requirement of Insulin by the patient indicates efficacy of implanted ICAs.

\section{Type II diabetes}

Type II diabetes, also called adult-onset diabetes, affects older, sedentary and overweight individuals with a family history of diabetes. Type 2 diabetes occurs when the body cannot use insulin effectively. This is called insulin resistance and the result is the same as with type 1 diabetes-increased levels of glucose in the blood.

Insulin resistance is a hallmark of type 2 diabetes (T2D). It has recently been shown that insulin resistance in skeletal muscles leads to production of myokines that impact negatively on $\beta$-cell function. Because of which over years of type 2 diabetes patients also require insulin.

Multiple Intramuscular Injections (IM) of Mesenchymal Stromal Cells (MSCs) at different sites would aid in countering the insulin resistance in T2D. These IM injections are expected to have dual effects in overcoming muscle insulin resistance. It is likely to modulate the micro environmental niche of insulin-insensitive myocytes under the influence of paracrine secretions from MSCs, in turn changing the myokine secretion pattern to positively regulate $\beta$-cell function. Further, it may stimulate the satellite cell population to generate new myocytes, which would be insulin-sensitive [6]. The other advantage of implantation of ADMSCs derived ICAs is they can remain viable for long time in the body since they are not attacked and destroyed by immune system like in type 1 diabetes.

Organ transplantation, cellular therapy, either from cadaveric transplantation or translated insulin secreting cells and stem cell therapy are in the forefront of the research in therapy for both the types of diabetes. Several options for tissue engineering include restoration of function to $\beta$ cells include (i) live pancreatic transplantation (ii) cadaveric pancreatic transplantation [7] and (iii) $\beta$ cell transplantation from multiple cadaveric pancreas. Pancreatic transplantation and allogenic transplantation of insulin secreting cells need immuno-suppression. Significant shortage of donor pancreas available for transplantation has led to the exploration of alternative sources of insulin-producing cells. These include primary $\beta$ cells derived from progenitor Embryonic Stem (ES) cells, Bone Marrow-Derived Mesenchymal Cells (BMC), liver cells and ADMSCs.

The present study is based on our national prize winning project awarded to us by Department of Biotechnology (DBT), funded by Government of India as "Differentiation of Human Adipose Tissue Derived Stem Cells to Islet Cell mass Aggregates (ICA) and its preparation for Clinical Application" conducted successfully at our Institution. To take it forward to clinical application the project was approved by Institutional Ethics Committee (IEC) as well as by Institutional Committee for Stem Cell Research (IC-SCR). It was registered as a clinical trial with Drug Controller General of India, reference no. ECR/201/Indt/GJ/2014. The research aims at providing the proof of concept that ADMSCs have paracrine, hypoglycemic and translineage translation properties. The ADMSCs were further trans- differentiated to glucose secreting ICAs.
This novel protocol is autologous, in conformity with ICMR guidelines 2013, is applicable to both the types of diabetes. This study would evolve an easily do-able, cost-effective, stem cell therapy for both types of diabetes without the need for post transplatation immunosuppression.

\section{Material and Methods}

The study was enrolled as a clinical trial CTRI No 2013/02/004619. A written consent was obtained from each patient. The recruitment was open ended, non randomized and non controlled basis.

\section{Selection of patients}

Inclusion criteria: Patients with either sex with age between 14 to 77; type I or II diabetes for more than 5 years duration. Patients with diabetes mellitus, as defined by fasting glucose measurement above 140 or more $\mathrm{mg} / \mathrm{dl}$ and post meal 2 hours glucose more than 200 to $350 \mathrm{mg} / \mathrm{dl}$, to avoid hypoglycemia after stem cell treatment, were enrolled.

Exclusion criteria: Patients with history of taking corticosteroids or NSAIDs, glycosaminoglycan, or suffering from active cardiac or respiratory disease; patients positive for markers for Hepatitis B, C, or HIV; and patients with history of allergic reactions were excluded from the study.

A total of seven patients ( 2 females of Type 1 and 5 males of type 2 diabetes) were included in the present study. All the seven patients fulfilled the above mentioned criteria. (Table 1)

\begin{tabular}{|c|c|c|c|c|c|}
\hline Patient & M/F & Age & Weight (Kg) & $\begin{array}{c}\text { Amount of aspirate } \\
\text { (cc) }\end{array}$ & $\begin{array}{c}\text { Total number } \\
\text { of Mononuclear } \\
\text { Cells }\end{array}$ \\
\hline 1 & F & 21 & 42 & 100 & $40 \times 10^{6}$ \\
\hline 2 & F & 14 & 33 & 140 & $108 \times 10^{6}$ \\
\hline 3 & M & 46 & 85 & 300 & $113 \times 10^{6}$ \\
\hline 4 & M & 64 & 84 & 400 & $170 \times 10^{6}$ \\
\hline 5 & M & 58 & 68 & 460 & $216 \times 10^{6}$ \\
\hline 6 & M & 47 & 96 & 500 & $228 \times 10^{6}$ \\
\hline 7 & M & 77 & 75 & 500 & $162 \times 10^{6}$ \\
\hline
\end{tabular}

Table 1: Demographic profile of patients enrolled for the study.

The patients were evaluated based on their blood investigation before commencement of therapy. This included complete blood count, blood sugar levels (FBS/PPBS), Blood urea, Serum creatinine, SGPT, HIV (I and II) antibody test, Hepatitis B surface antigen \& HCV antibody test, Prothrombin time with INR (International Normalized ratio), Thyroid Stimulating Hormone (TSH) levels.

\section{Surgical Procedure}

Adipose tissue was aspirated by a trained plastic surgeon with specially designed aspiration cannulae (Figure 1) under local anesthesia and sedation. Approximately 100 to 150 in case of type I diabetes and up to $500 \mathrm{cc}$ in type II diabetic individuals, of lipoaspirate was collected from lower abdominal subcutaneous fat in the operating room and transferred to a sterile container. The samples were processed in GMP Class V laboratory for cell isolation under strict aseptic conditions.

\section{Laboratory Procedure}

We have standardized our laboratory protocols in consonance with Good Laboratory Practises (GLP). The protocol is being patented. The steps are briefly noted as below; 


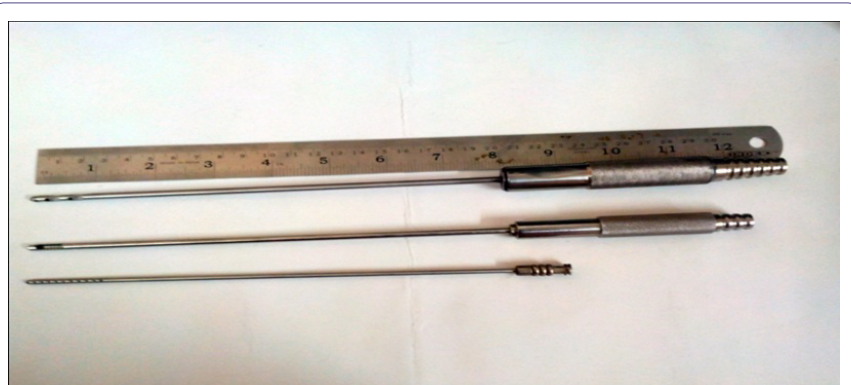

Figure 1: Specialized Canulae.

\section{MSCs isolation}

Stem cells were isolated using standard protocol as follows;

Adipose collected was washed twice with PBS ( $\mathrm{pH}$ 7.4) for removal of blood fraction. The tissue was then subjected to enzymatic digestion using $0.2 \%$ (W/V) Collagenase type 1 (Gibco Cat \#17100017) in DMEM: F12 media with antibiotics at $37^{\circ} \mathrm{C}$ in $\mathrm{CO}_{2}$ incubator (Thermo scientific, Forma series II) with periodical gentle shaking for $2 \mathrm{~h}$. The ADMSCs were isolated from fat tissue by pelleting cells at $2000 \mathrm{~g}$ on REMI centrifuge for $10 \mathrm{~min}$. The supernatant was removed and pellet was washed twice with PBS. The RBCs in the pellet were lysed with D/W. The pellet of Mono Nuclear Cells was seeded in flasks with density of 2000-3000 cells $/ \mathrm{cm}^{2}$ area in DMEM: F12 (1:1) with 10\% FBS (Gibco Cat \# 10270-106).

The SVF cells were cultured in tissue adherent flask in an incubator at $37^{\circ} \mathrm{C}, 5 \% \mathrm{CO}_{2} / 95 \%$ air and $95 \%$ humidity for 18 days with medium replacement every 2-3 days. The ADMSCs adherent cells are obtained.

\section{Phenotypic Characterization of ADMSCs}

Phenotypic characterization of ADMSCs was done with positive markers for MSCs: CD29, CD44, CD90, CD105, and the negative markers CD34, CD45 and HLA- DR.

The mesenchymal stem cells were further cultured in DMEM:F12 (1:1) supplemented with $10 \%$ FBS for 5-7 days, staining was performed on fixed, permeabilized monolayers of mesenchymal cells grown on coverslips.

The cells were washed with PBS, fixed for 10 minutes at $37^{\circ} \mathrm{C}$ in $2 \%$ paraformaladehyde in PBS. Normal Donkey serum in PBS was used to block nonspecific binding of the primary antibody. The slides were then incubated over night at $4^{\circ} \mathrm{C}$ with $\mathrm{CD} 29, \mathrm{CD} 44, \mathrm{CD} 90$, CD105 non-labeled mouse anti-human antibodies (ABCAM, USA), followed by Cy3 and Alexa fluor 488 anti-mouse and anti-rabbit IgG antibodies (Jackson Immuno Research) for $40 \mathrm{~min}$ at room temperature. The coverslips were mounted and viewed with FLOID microscope (applied biosystems) (Figure 2)

For negative markers namely CD34, CD45 and HLA- DR, outsourcing was done at Baroda Clinical Laboratory by a qualified cell cytologist (Figure 3).

\section{Translation of ADMSCs to ICAs}

Differentiation of ADMSCs to ICAs was carried out with a modified protocol at our laboratory that was originally reported by Chandra et al., [8]. Our improved protocol yields insulin secreting cells in about 10 days. They are further enriched to ICAs by $14-16$ days. ICA's showed positive staining for insulin and c-peptide.
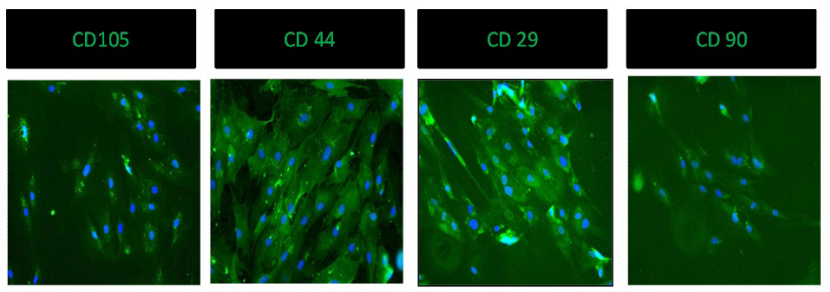

Figure 2: Positive marker studies for CD - 105, CD - 44, CD - 29, CD - 90.
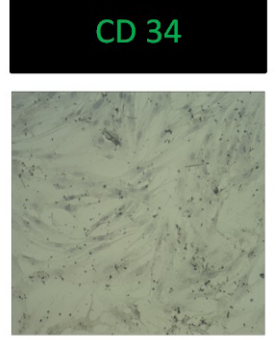

Figure 3: Negative marker studies for CD - 34, CD - 45, HLA-DR.

The confirmed ADMSCs were plated to low attachment plates (Himedia Laboratories) at density of $10^{6} \mathrm{ells} / \mathrm{cm}^{2}$ in DMEM: F12 until $80 \%$ confluency is achieved. Thereafter cells were put in Serum Free Media according to protocol of Chandra et al. Briefly, differentiation was carried out in three stages as reported earlier by Chandra et al., [8], cells were resuspended in SFM-A containing DMEM/F12 (1:1) (GIBCO) with $17.5 \mathrm{mM}$ glucose, $1 \%$ BSA Cohn fraction V, fatty acid free (\#A8806, Sigma-Aldrich), 16 Insulin-transferrin-selenium (ITS $5 \mathrm{mg} / \mathrm{L}$ insulin $+5 \mathrm{mg} / \mathrm{L}$ transferrin $+5 \mathrm{mg} / \mathrm{L}$ selenium), $4 \mathrm{nM}$ activin A, $1 \mathrm{mM}$ sodium butyrate, $50 \mathrm{mM}$ 2-mercaptoethanol and $2 \mathrm{ng} / \mathrm{ml}$ fibroblast growth factor. The cells were cultured in this media for 2 days.

On 3rd day media was changed to SFM-B that contained DMEM/ F12 (1:1) with $17.5 \mathrm{mM}$ glucose, $1 \%$ BSA, ITS and $0.3 \mathrm{mM}$ taurine. The cell aggregates were cultured in this medium for another 2 days.

Cells were further shifted to SFM-C on 5th day. SFM-C contained DMEM/F12 (1:1) with $17.5 \mathrm{mM}$ glucose, 1.5\% BSA, ITS, $3 \mathrm{mM}$ Taurine, $100 \mathrm{nM}$ Glucagon-Like Peptide 1 (GLP-1) (amide fragment 7-36, Sigma Aldrich), $1 \mathrm{mM}$ nicotinamide and 16 Non-Essential Amino Acids (NEAA). The cell aggregates were fed with fresh SFM-C medium every 2 days for another 12-14 days. The changes in cell morphology and their paracrine effect is seen if figure 4 . Briefly the steps are:

1. hADMSCs were grown in low adherence culture dishes and exposed to Serum Free Media (SFM-A) for 2 days. By 24-48 hrs, cells migrated and clustered to become Islet Like Cells Aggregates (ICAs),

2. Day3-ICAs were exposed to SFM supplemented with low levels of taurine (SFM-B), a non-essential amino acid involved in the development of pancreatic b-cells. After 2 days of incubation in SFM-B, in the final stage of differentiation,

3. ICAs were exposed to differentiation media supplemented with b-cell maturation factors like GLP-1 and Nicotinamide (SFM-C)

\section{Immunocytochemistry of Differentiated ICAS}

Five ICAs were picked manually from cultured plates. ICAs were fixed with freshly prepared $4 \%$ Para-Formaldehyde (PFA). Slides were 
Citation: Vyas BK, Vyas RB, Ansarullah A, Marathe A, Thadani JM, et al. (2016) Therapeutic Application of Autologous ADMSCS (Adipose Derived Mesenchymal Stem Cells) and Islet like Cell Aggregates (ICAS) Derived from them in Type 1 and 2 Diabetes Mellitus - A Proof of Concept Study. J Stem Cell Res Dev Ther 3: 08.

- Page 4 of 6 •

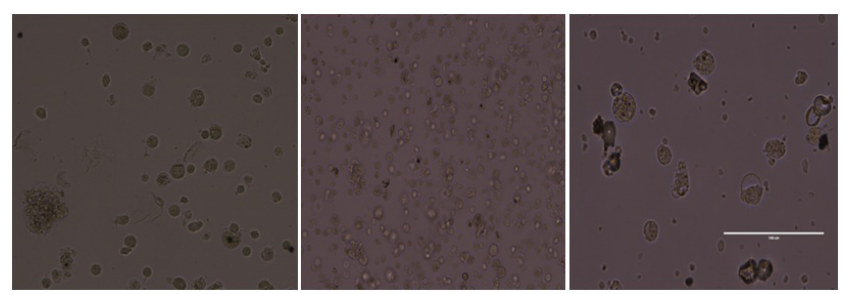

Figure 4: SFM - A, SFM - B, SFM - C.

prepared from the block so processed, and stained with DAPI for nuclear staining. Slides were observed under Carl Zeiss LSM 700 Confocal Microscope (Figure 5).
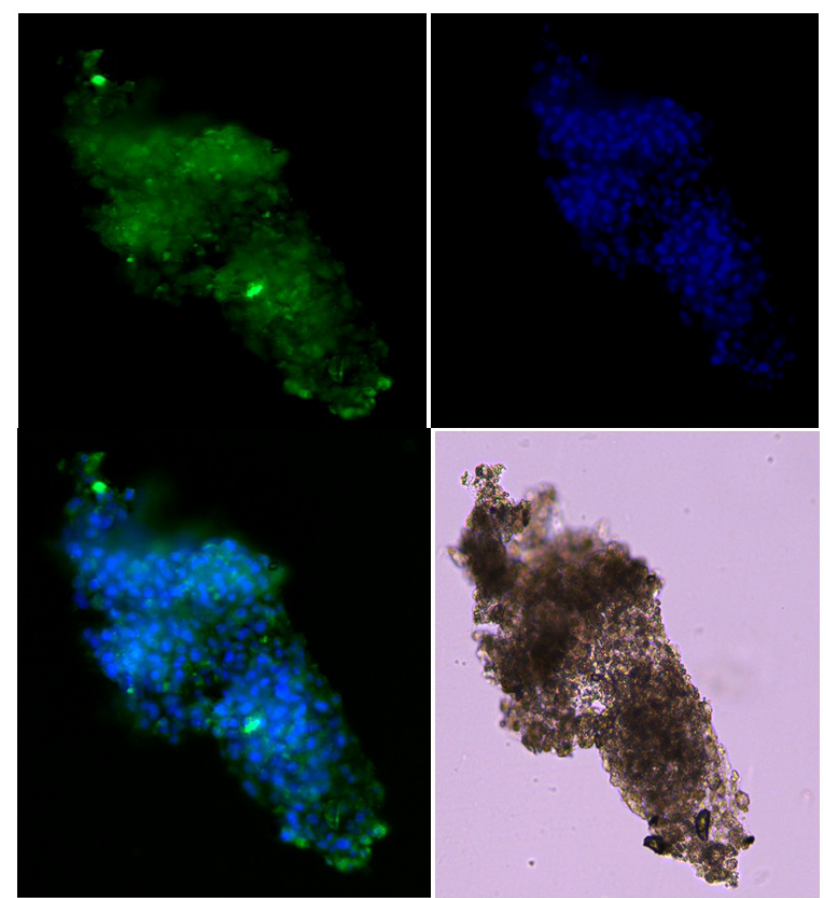

Figure 5: Merged image of ICA under confocal microscope.

ADMSCs were differentiated into Islet-Like Cell Aggregates (ICA’s) and showed positive staining for Dithizone demonstrating affinity for insulin (Figure 6).

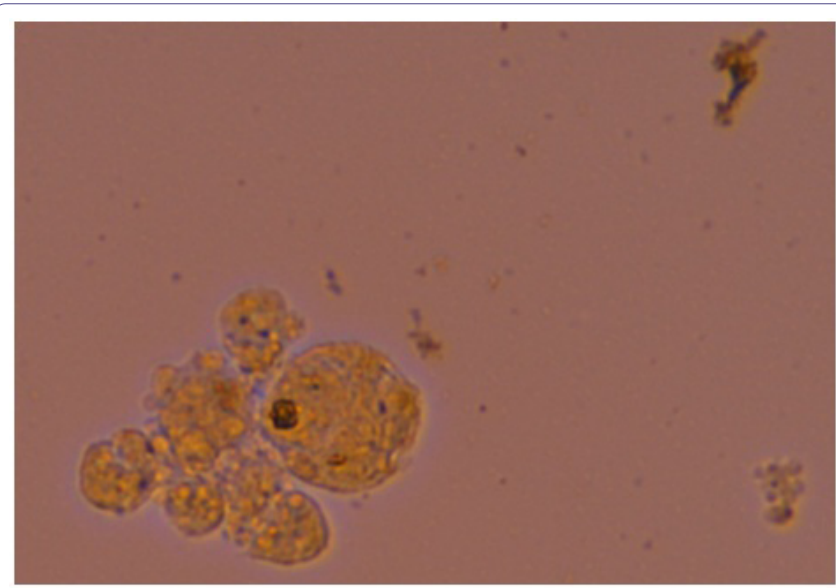

Figure 6: Dithizone staining of ICAs.

The insulin secretion and glucose sensitivity of ICAs was tested in vitro by increasing levels of glucose in the media and tested for insulin production. The insulin levels secreted by ICAs increased according to increased glucose levels. This established the insulin secreting function and glucose sensitivity of ICAs.

\section{Clinical Protocol for Administration}

1. Intramuscular injections of ADMSCs

One half of SVF isolated, approximately 1-2 million/kg body weight, were injected intramuscularly into the subjects after diluting in $4 \mathrm{cc}$ of Isolyte M. $1 \mathrm{cc}$ of this suspension was injected in each of deltoids and gluteus maximus muscles with 21 no. needle [9].

2. Half of the SVF was processed for culture to get pure MSCs. They were passaged twice to get more number of pure MSCs. After differentiation to ICAs, approximately up to 1000 ICA were injected percutaneously directly into the liver using 21 no. needle.

The time interval between the intramuscular SVF injection and ICAs implantation was about one month.

\section{Results}

The results of the study are shown in table 2 .

\section{Summary and Outcome}

\section{Type 1 diabetes- Juvenile diabetes}

Patient 1: One of the juvenile diabetic patient followed for more than year is noteworthy. The female patient of $21 \mathrm{yrs}$, was treated with our protocol for juvenile diabetes. The clinical improvement in 12 months was noticed that her blood sugar dropped from $360 \mathrm{mg}$ to $260 \mathrm{mg}$; increase in weight from $42 \mathrm{~kg}$ to $48 \mathrm{~kg}$.; hemoglobin level increased from $7.8 \%$ to $13.2 \%$ and, her insulin dosage decreased from 24 Units of Mixtard to 16 Units in the morning and 12 units to 10 units in the evening. Initially, she had complains of restlessness, inactiveness and drowsiness but eventually her life style improved. She started feeling fresh, enthusiastic and was able to work for 8-10 hours. She restarted her studies for chartered accountancy.

Patient 2: Female aged 14. She was on morning and evening dose of $20 \& 12$ units plain insulin with blood sugar level as indicated in the table (FBS $330 \mathrm{mg} / \mathrm{dl}$ and PPBS $140 \mathrm{mg} / \mathrm{dl}$ ). As the case with type 1 diabetes she was lean and she also was trying to control her diabetes by dieting. Following the treatment with our protocol her insulin requirement initially came down to 10 units \& 6 units respectively. She was feeling much better and she increases her physical activity but had not followed our reccommended diet pattern. Later her insulin requirement increased and her blood sugar levels were not much affected. This could possibly because of less number of cells and in turn ICAs available for transplantation and intramascular injections. She has put on some weight and maintained a haemoglobin level around $12 \mathrm{gm}$.

\section{Type II Diabetes; maturity onset diabetes}

All the subjects were having uncontrolled diabetes, with insulin ( 2 patients) and oral hypoglycemic agents ( 3 patients). 1 patient had Diabetic Retinopathy as a complication.

Patient 3: Male aged 46, post treatment his blood sugar level came down as per table (FBS $217 \mathrm{mg} / \mathrm{dl}$ and PPBS $215 \mathrm{mg} / \mathrm{dl}$ to FBS 163 $\mathrm{mg} / \mathrm{dl}$ and PPBS $170 \mathrm{mg} / \mathrm{dl}$ ). He also had diabetic retinopathy and patient felt improvement in the vision which was verified later with optimetry. 
Citation: Vyas BK, Vyas RB, Ansarullah A, Marathe A, Thadani JM, et al. (2016) Therapeutic Application of Autologous ADMSCS (Adipose Derived Mesenchymal Stem Cells) and Islet like Cell Aggregates (ICAS) Derived from them in Type 1 and 2 Diabetes Mellitus - A Proof of Concept Study. J Stem Cell Res Dev Ther 3: 08.

- Page 5 of 6 -

\begin{tabular}{|c|c|c|c|c|c|c|c|c|c|}
\hline \multirow[t]{2}{*}{ Subject } & \multirow[t]{2}{*}{ Gender } & \multicolumn{2}{|c|}{$\begin{array}{c}\text { Glucose Level } \\
\text { (Before Induction) }\end{array}$} & \multicolumn{2}{|c|}{$\begin{array}{l}\text { Glucose Level } \\
\text { (After Induction) }\end{array}$} & \multicolumn{2}{|c|}{$\begin{array}{c}\text { Insulin Dose } \\
\text { (Before Induction) }\end{array}$} & \multicolumn{2}{|c|}{$\begin{array}{c}\text { Insulin Dose } \\
\text { (After Induction) }\end{array}$} \\
\hline & & $\begin{array}{l}\text { Fasting } \\
\mathrm{mg} / \mathrm{dl}\end{array}$ & $\begin{array}{l}\text { PPBS } \\
\mathrm{mg} / \mathrm{dl}\end{array}$ & $\begin{array}{l}\text { Fasting } \\
\text { mg/dl }\end{array}$ & $\begin{array}{l}\text { PPBS } \\
\mathrm{mg} / \mathrm{dl}\end{array}$ & Morning & Evening & Morning & Evening \\
\hline 1 & $F(21)$ & 180 & 360 & 110 & 260 & $24 U$ & $12 U$ & $16 U$ & $10 U$ \\
\hline 2 & $F(14)$ & 330 & 140 & 330 & 140 & $20 \mathrm{U}$ & $12 U$ & $10 U$ & $6 U$ \\
\hline 3 & $M(46)$ & 217 & 215 & 163 & 170 & Tab & Tab & Tab & Tab \\
\hline 4 & M (64) & 140 & 206 & 120 & 160 & Tab & Tab & Tab & Tab \\
\hline 5 & M (58) & 127 & 201 & 100 & 150 & Tab & Tab & Tab & Tab \\
\hline 6 & $\mathrm{M}(47)$ & 249 & 198 & 130 & 160 & $\begin{array}{l}\text { Mixtard } \\
50 U\end{array}$ & $\begin{array}{l}\text { Crystaline } \\
40 \mathrm{U}\end{array}$ & $\begin{array}{l}\text { Mixtard } \\
30 \mathrm{U}\end{array}$ & $\begin{array}{l}\text { Crystaline } \\
20 \mathrm{U}\end{array}$ \\
\hline 7 & $M(78)$ & 195 & 267 & 110 & 130 & $22 \mathrm{U}$ & $18 U$ & Tab & No drug \\
\hline
\end{tabular}

Table 2: Pre treatment and Post treatment (With IM ADMSCS and intra hepatic ICAs) blood glucose level and insulin dose.

Patient 4: Male, 64 years was on oral hypoglycemic drug, glibenclamide $5 \mathrm{mg}$ and metformin $500 \mathrm{mg}$ B.D. With same dosage of oral anti-diabetic drugs his blood sugar came down from FBS $140 \mathrm{mg} /$ $\mathrm{dl}$ and PPBS $206 \mathrm{mg} / \mathrm{dl}$ to FBS $120 \mathrm{mg} / \mathrm{dl}$ and PPBS $160 \mathrm{mg} / \mathrm{dl}$.

Patient 5: Male, 58 years was on oral hypoglycemic drugs, Glemulin $500 \mathrm{mg}$ B.D. His oral dosage was reduced half after treatment and his blood sugar levels came down from FBS $127 \mathrm{mg} / \mathrm{dl}$ and PPBS $201 \mathrm{mg} / \mathrm{dl}$ to FBS $100 \mathrm{mg} / \mathrm{dl}$ and PPBS 150mg/dl. Over all he was feeling better and enthusiastic.

Patient 6: Male, aged 47 was habituated to alcohol everyday evening. He had uncontrolled diabetes inspite of high inulin dosage. His insulin requirement was reduced from $50 \mathrm{U}$ mixtard in the morning and $40 \mathrm{U}$ of crystaline insulin in the evening to $30 \mathrm{U}$ and $20 \mathrm{U}$. The blood sugar levels came down from FBS $249 \mathrm{mg} / \mathrm{dl}$ and PPBs $198 \mathrm{mg} / \mathrm{dl}$ to FBS $130 \mathrm{mg} / \mathrm{dl}$ and PPBS $160 \mathrm{mg} / \mathrm{dl}$.

Patient 7: Male, 78 years known diabetic for last 30 years. The patient was on oral antidiabetic drug for many years but since last 1 year he was advised plain Insulin 22 units morning and 18 units in the evening as the diabetes was not controlled by oral antidiabetic drugs. Post therapy, he was taken off the insulin and was given $2.5 \mathrm{mg}$ of Daonil in the morning. His blood sugar levels were maintained at FBS $110 \mathrm{mg} / \mathrm{dl}$ and PPBS $130 \mathrm{mg} / \mathrm{dl}$.

\section{Discussion}

Adipose tissues isolated from human lipoaspirates are also called Adipose-Derived Stromal Cells (ADSCs) with several priorities over other sources in the way that they can be accessed easily in large amounts and possess differentiation capacities similar to BMMSCs [10].

Moreover, several experimental studies have revealed that ADSCs even have greater proliferation, differentiation and immunomodulatory potencies compared with BMMSCs [11-15].

In the studies by Timper et al., [16] and Eberhardt et al., [17] human Adipose tissue-derived MSCs (AD-MSCs) from four donors were expanded in a fibroblast growth factor-containing medium. These cells expressed stem cell markers including Isl1 mRNA, which is essential for the generation of pancreatic islet cells. Moreover, they observed up regulation of transcription factors Ipf1, Isl1 and Ngn3 and islet gene insulin, glucagon and somatostatin, in addition to the expression of C-peptide in differentiated cells.

Chandra et al., [8] showed that AD-MSCs from murine epididymis could differentiate into insulin-producing aggregates under a ten-day inductive protocol.
In a recent study by Karaoz et al., it was demonstrated that AD-MSCs differentiate into IPCs after 38-day coculture with islet cells. Insulin and C-peptide production were confirmed by ELISA and immunostaining.

Taken together with the advantages that harvesting and producing AD-MSCs appear to be more practical and less invasive in humans compared with BMMSCs, this population of MSCs can be considered as an alternative source of IPCs.

Stem cell based therapy, both autologous and allogenic, and organ transplantation are the emerging therapeutics in regenerative medicine. Transplantation of pancreas, from living as well as cadaveric donors is yet to find a place in clinical domain.

Our innovative protocol is derived from 2 different products from the same source at a single operative procedure. Multipotent multilineage mesenchymal stem cells from AT are utilised in the dosage of 1-2 million/kg cells intra muscularly. There are several rejuvenating properties of mesenchymal stem cells including immunosuppression. Recently, hypoglycemic property is also established [10]. Our protocol utilises the immuno protection and hypoglycemic properties as step 1 .

Transplantation of autologous insulin secreting cells obtained from various samples through Edmonton protocol requires a mini-laparotomy. Our protocol utilises direct percutaneous/ intrahepatic injection of ICAs. It has advantage over Edmonton protocol in being less invasive. We have proved and utilised translineage translation of ADMSCs to ISCs.

The dosage of MSCs as 1-2 million/kg body weight is now well established. The dosage of ICAs is arbitrarily considered to be up to 30,000 ICAs. Translation od ADMSCs to ICAs in vitro is a fastidious process and scaling up the production of ICAs to that number is very difficult. The number of ICAs used in the present study is much lower but it was used as the lowest dose so that there is no fear of patient developing hypoglycemia after transplant. The drug requirement in every diabetic is variable. Injecting a small number of ICA provided the proof that blood sugar levels were lowered and, there was no hypoglycemia in any subject. The aim of the research is to provide proof of the concept that functional ICAs can be trans differentiated from ADMSCs. Lowering of blood glucose levels in type 1 diabetic patients was minimal. The possible reasons for this could be : 1 only small amount of lipoaspirate is collected from them as the type 1 diabetic patients are very lean and do not have much adipose and secondly the implanted ICAs may not survive for long because of autoimmune attack. We also propose allogenic ICAs from MSCs and 
Citation: Vyas BK, Vyas RB, Ansarullah A, Marathe A, Thadani JM, et al. (2016) Therapeutic Application of Autologous ADMSCS (Adipose Derived Mesenchymal Stem Cells) and Islet like Cell Aggregates (ICAS) Derived from them in Type 1 and 2 Diabetes Mellitus - A Proof of Concept Study. J Stem Cell Res Dev Ther 3: 08.

- Page 6 of $6 \bullet$

some biocompatible cell impermiable scaffold to protect implanted ICAs. The results in case of type 2 diabetes are more encouraging. This could be because of additional insulin secretion from ICAs and intramuscular injection of SVF can further help in utilization of insulin by sensitization of insulin receptors on muscles by paracrine effect.

\section{Conclusion}

A novel protocol utilising two products, derived from single source is described. The study proves benefit in glucose lowering in patients with type 2 diabetes. In case of type 1 diabetic patients we suggest scaling up of ICAs to larger number and immunoprotective devise after implantation. The study concludes that management of diabetes can be improved with the present concept.

\section{Acknowledgement}

The Department of Biotechnology (DBT), Government of India funded project: SBIRI ref no. BT/SBIRI/1009/6-B20/2012. We acknowledge guidance from Dr. Ramesh Bhonde, Dean, Manipal Institute of Regenerative Medicine and Dr. Bharat Chattoo, Dean, Genomic Research Centre, for permiting the use of confocal microscope. Dr. Udyayan Kachhi contributed for negative marker study at the laboratory. The research was awarded Best Research Presentation at Biotechnology Industrial Research Assistance Council (BIRAC) meet III, Sept, 2014.

\section{References}

1. Zuk PA, Zhu M, Mizuno H, Huang J, Futrell JW, et al. (2001) Multilineage cells from human adipose tissue: implications for cell-based therapies. Tissue Eng 7: 211-228.

2. Monfort A, Izeta A (2012) Strategies for Human Adipose Tissue Repair and Regeneration. Journal of Cosmetics, Dermatological Sciences and Applications 2: 93-107.

3. Pittenger MF, Mackay AM, Beck SC, Jaiswal RK, Douglas R, et al. (1999) Multilineage potential of adult human mesenchymal stem cells. Science 2 : 143-147.

4. Paek HJ, Kim C, Williams SK (2014) Adipose stem cell-based regenerative medicine for reversal of diabetic hyperglycemia. World J Diabetes 5: 235-243.

5. Ezquer M, Arango-Rodriguez M, Giraud-Billoud M, Ezquer F (2014) Mesenchymal Stem Cell Therapy in Type 1 Diabetes Mellitus and Its Main Complications: From Experimental Findings to Clinical Practice. J Stem Cell Res Ther 4: 8.
6. Gopurappilly R, Bhonde R (2012) Can multiple intramuscular injections of mesenchymal stromal cells overcome insulin resistance offering an alternative mode of cell therapy for type 2 diabetes? Med Hypotheses 78: 393-395.

7. Farney AC, Cho E, Schweitzer EJ, Dunkin B, Philosophe B, et al. (2000). Simultaneous cadaver pancreas living-donor kidney transplantation: a new approach for the type 1 diabetic uremic patient. Ann Surg 232: 696-703.

8. Chandra V, Swetha G, Muthyala S, Jaiswal AK, Bellare JR, et al. (2011) Islet-like cell aggregates generated from human adipose tissue derived stem cells ameliorate experimental diabetes in mice. PLoS ONE 6: 20615.

9. Rafael E, Tibell A, Rydén M, Lundgren T, Sävendahl L, et al. (2008) Intramuscular autotransplantation of pancreatic islets in a 7-year-old child: a 2-year follow-up. Am J Transplant 8: 458-462.

10. Zuk PA, Zhu M, Ashjian P, De Ugarte DA, Huang Jl, et al. (2002) Human adipose tissue is a source of multipotent stem cells. Mol Biol Cell 13: 4279-4295.

11. Kim Y, Kim H, Cho H, Bae Y, Suh K, et al. (2007) Direct comparison of human mesenchymal stem cells derived from adipose tissues and bone marrow in mediating neovascularization in response to vascular ischemia. Cell Physiol Biochem 20: 867-876.

12. Pendleton C, Li Q, Chesler DA, Yuan K, Guerrero-Cazares H, et al. (2013) Mesenchymal stem cells derived from adipose tissue vs bone marrow: in vitro comparison of their tropism towards gliomas. PLoS ONE 8: 58198.

13. Kern S, Eichler H, Stoeve J, Klüter H, Bieback K (2006) Comparative analysis of mesenchymal stem cells from bone marrow, umbilical cord blood, or adipose tissue. Stem Cells 24: 1294-1301.

14. Melief SM, Zwaginga JJ, Fibbe WE, Roelofs H (2013) Adipose tissue-derived multipotent stromal cells have a higher immunomodulatory capacity than their bone marrow-derived counterparts. Stem Cells Transl Med 2: 455-463.

15. Lee RH, Kim B, Choi I, Kim H, Choi HS, et al. (2004) Characterization and expression analysis of mesenchymal stem cells from human bone marrow and adipose tissue. Cell Physiol Biochem 14: 311-324.

16. Timper K, Seboek D, Eberhardt M, Linscheid P, Christ-Crain M, et al. (2006) Human adipose tissue-derived mesenchymal stem cells differentiate into insulin, somatostatin, and glucagon expressing cells. Biochem Biophys Res Commun 341: 1135-1140.

17. Eberhardt M, Salmon P, von Mach MA, Hengstler JG, Brulport M, et al. (2006) Multipotential nestin and IsI-1 positive mesenchymal stem cells isolated from human pancreatic islets. Biochem Biophys Res Commun 345: 1167-1176. 